\title{
Research on the relationship between the imbalance of regional economic growth and the allocation of financial resources
}

\author{
Rong Sun ${ }^{1 *}$ \\ ${ }^{1}$ Beijing Jiaotong University, School of economics and management, China
}

\begin{abstract}
Since the reform and opening up, China's economic growth has attracted worldwide attention, and people's living standards have been significantly improved. However, China's economic growth shows an unbalanced trend, that is, the level of economic growth in the central and western regions is far lower than that in the eastern regions, and the gap between regional economic growth is still widening, which seriously hinders the construction of a harmonious society in China. The allocation of financial resources will play a mainstay role in economic development. Therefore, it is important to pay attention to the relationship between the imbalance of regional economic growth and the allocation of financial resources. This paper chooses GDP per capita to represent regional economy, and chooses deposit loan ratio, industrial structure, financial expenditure per capita, foreign capital per capita and insurance premium per capita to represent financial resource allocation. Using the above variables to build a panel regression model, according to the coefficient of the regression analysis results, this paper puts forward relevant suggestions to balance regional economic growth.
\end{abstract}

\section{Introduction}

At present, China's economic growth has been significantly improved, but the problem of unbalanced regional economic growth is becoming more and more serious. This unbalanced development has brought obvious negative effects: first, it is very unfavorable to social stability, the other is that it will distort regional economic relations, limit the economic growth space of backward areas and affect the efficiency of economic operation, resulting in the slow economic development in underdeveloped areas ${ }^{[1]}$.

It is not only China, but also other parts of the world. The reason why the imbalance of regional economic growth has occurred, scholars put forward many views, some people think that the natural environment and geographical location have caused this problem, some people think that government policy also plays a role in some aspects. Barthel's research in 2017 found that China's implementation of the strategy of giving priority to the development of the eastern coastal areas, policy from the original balanced development to nonequilibrium development mode, with preferential financial and financial policies to attract domestic and foreign investment, rapid gathering of economic and financial resources, so the continuous development of the eastern region and the central and western region gap is widening ${ }^{[2]}$. However, this paper holds that the difference between the degree of financial resources abundance and the efficiency of financial resources allocation may be the more important reason for the imbalance of regional economic growth in China. On the one hand, financial resources are the important sources of funds to promote economic development, which can serve the economic growth well ${ }^{[3]}$; on the other hand, regional economic growth creates a good environment for financial resources allocation, which can flow fully, which is conducive to optimizing the dynamic allocation of financial resources ${ }^{[4]}$. Therefore, it is beneficial to study how to improve the ability of regional financial resources allocation, which is conducive to promoting economic prosperity in a certain region, and also for the government to control or reduce the imbalance of regional economic growth.

In order to solve this problem, this paper selects the GDP per capita to represent regional economy, and chooses deposit loan ratio, industrial structure, financial expenditure per capita, foreign capital per capita and insurance premium per capita to represent financial resource allocation. In this paper, Wilson coefficient is used to study the regional imbalance. Then according to the results of Hausmann test, the panel regression model of each region is constructed. Finally, according to the results of the model, this paper draws conclusions and puts forward relevant suggestions.

The contributions of this paper are as follows: first, most of the existing studies focus on economic growth, and less in-depth study of regional economic growth imbalance. Second, with the changes of economy and society, the past research results may no longer be applicable to the current economic situation.

\footnotetext{
*Corresponding author: 2457026477@qq.com
} 


\section{Overview and current situation}

China has the characteristics of large land area and large population. In order to promote the overall economic development, different regions have adopted different development strategies. Due to the influence of economic policy, physical geography, financial resources and other factors, the speed of economic development in some areas is faster, while the speed of economic development in some areas is slower, which makes regional economic growth different. This phenomenon is known as the imbalance of regional economic growth. Shenzhen, for example, has achieved rapid economic development relying on the reform and opening up and its geographical advantages close to Hong Kong. The allocation of financial resources refers to the reasonable allocation of the financial resources it contains, providing different financial sectors with the type and scale of financial resources suitable for their own development, so that different types and degrees of economic sectors can achieve their own development, so as to promote the overall economic growth ${ }^{[5]}$.

The differences of regional economic growth and financial resources allocation can be divided into absolute differences, relative differences and comprehensive differences. The absolute difference is greatly affected by the economic development base or level, and the relative difference is more suitable for the comparison between two regions. Therefore, the third method is used to comprehensively reflect the differences in economic growth and financial resource allocation between all regions ${ }^{[6]}$. Wilson, an American scholar, first proposed to use the proportion of the population of each region in the total population as the weight, so as to obtain the weighted variation coefficient $\mathrm{V}_{\mathrm{W}}$ (Wilson coefficient). The larger the coefficient is, the greater the regional difference is. The formula is as follows:

$$
V_{W}=\frac{1}{\bar{x}} \sqrt{\left(x_{i}-\bar{x}\right)^{2} * \frac{p_{i}}{p}}
$$

$x_{i} \longrightarrow$ horizontal value of area $\mathrm{i}, \frac{p_{i}}{p} \longrightarrow$ Proportion of population in different regions to total population,

$\bar{x}=\sum x_{i} * \frac{p_{i}}{p}$.

The Wilson coefficient of per capita GDP is about 0 . 4 , which indicates that the regional economic gap is large. As for the allocation of financial resources, it can be seen from the figure that the regional difference of per capita utilization of foreign capital is the largest, the coefficient is about 1 ,while the regional difference of deposit loan ratio is small. The regional imbalance of industrial structure and per capita premium tends to decrease. However, the gap of financial expenditure per capita tends to expand.

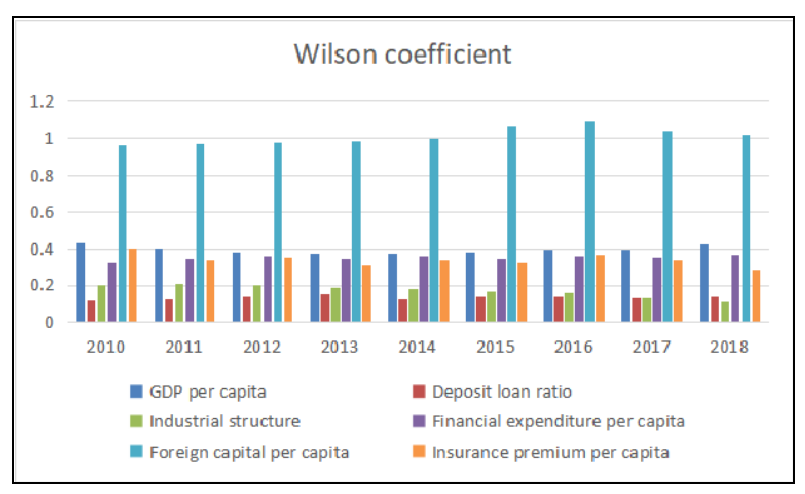

Fig. 1. Wilson coefficient from 2010 to 2018.

\section{Empirical analysis}

Based on the previous analysis, there may be a certain relationship between the allocation of financial resources and the level of economic development. This chapter uses the panel model to make an empirical analysis of the relationship between the two in China's three regions, and further proves the importance and necessity of optimizing the allocation of financial resources for balancing regional economic growth.

In this part, firstly, the variable selection is carried out. Secondly, descriptive statistics of variables and the necessary unit root test and Hausmann test before the construction of the model are carried out. Finally, the regression results of the model are shown.

\section{1 Variable selection}

Using the panel data of China's provinces from 2010 to 2018, the data source is China Statistical Yearbook.

This paper selects GDP per capita as economic growth variable, deposit loan ratio(DLR) and industrial structure(IS) as explanatory variables, and financial expenditure per capita(FE), foreign capital per capita(FC) and insurance premium per capita(IP) as control variables. All variables are logarithmic.

Therefore, the model can be expressed as follows: $\ln G D P_{i t}=c+a_{l} \ln D L R_{i t}+a_{2} \ln I S_{i t}+\beta_{I} \ln F E_{i t}+\beta_{2} \ln F C_{i t}+$ $\beta_{3} \ln I P_{i t}+\varepsilon_{i t}$

\section{2 Empirical test}

\section{2. 1 Descriptive statistics}

For the above indicators, there are regional differences among and within the three regions. According to the results of descriptive statistical analysis, in the eastern region with good allocation of financial resources, the per capita GDP is higher; in the central and western regions where the allocation of financial resources is relatively poor, the per capita GDP is also low.

Table 1. Descriptive statistics.

\begin{tabular}{|c|c|c|c|}
\hline Regions & Eastern & Central & Western \\
\hline GDP & 71451.61 & 38974.21 & 37603.63 \\
\hline
\end{tabular}




\begin{tabular}{|c|c|c|c|}
\hline DLR & 0.74 & 0.72 & 0.79 \\
\hline IS & 0.51 & 0.41 & 0.43 \\
\hline FE & 1.82 & 1.60 & 3.42 \\
\hline FC & 109.33 & 20.31 & 19.14 \\
\hline IP & 0.34 & 0.24 & 0.23 \\
\hline
\end{tabular}

\section{2. 2 Unit root test}

The purpose of stationarity test is to eliminate the problem of pseudo regression. Pseudo regression means that sometimes the correlation between data is very strong, but there is no realistic correlation between them, so it is impossible to analyze them accurately. This paper uses unit root test to test the stationarity of data. From the ADF test results, under the $10 \%$ confidence level, the first-order difference series of the three regions are stable, that is, they are all first-order single integral series.

\section{2. 3 Hausman Test}

Hausmann test can determine whether to choose fixed effect model or random effect model, and its original hypothesis is to use random effect model. Therefore, according to the test results, the fixed effect model is used in the eastern regions and the western regions, and the random effect model is used in the central regions.

Table 2. Hausman Test.

\begin{tabular}{|c|c|c|}
\hline Cross-section random & Chi-Sq. Statistic & Prob. \\
\hline Eastern Regions & 43.223263 & 0 \\
\hline Central regions & 2.343486 & 0.7999 \\
\hline Western Regions & 58.966034 & 0 \\
\hline
\end{tabular}

\section{3 Econometric model}

Through the above test, we can determine the form of panel regression model for each region. From the regression results, we can see that the adjusted R-square is greater than 0.85 in each model, which indicates that the fitting degree of the equation is very high.

Table 3. Model results.

\begin{tabular}{|c|c|c|c|}
\hline & Eastern Region & Central Region & Western Region \\
\hline $\mathrm{c}$ & $10.79587^{*}$ & $9.852177^{*}$ & $9.368255^{*}$ \\
\hline & $(-47.18343)$ & $(38.163)$ & $(-40.5103)$ \\
\hline $\ln \mathrm{LLR}$ & $0.289393^{*}$ & 0.181962 & -0.01393 \\
\hline & $(-2.742808)$ & $(1.145922)$ & $(-0.179743)$ \\
\hline $\operatorname{lnIS}$ & $-0.544571^{*}$ & 0.078205 & -0.209136 \\
\hline & $(-3.393004)$ & $(0.444324)$ & $(-1.623457)$ \\
\hline $\operatorname{lnFE}$ & $0.743781^{*}$ & $0.866695^{*}$ & $0.945314^{*}$ \\
\hline & $(-12.9617)$ & $(9.171274)$ & $(-11.07302)$ \\
\hline $\operatorname{lnFC}$ & -0.035886 & $0.099853^{* * *}$ & $0.073964^{* * *}$ \\
\hline & $(-0.847351)$ & $(1.726147)$ & $(-1.790293)$ \\
\hline
\end{tabular}

\begin{tabular}{|c|c|c|c|}
\hline $\operatorname{lnIP}$ & $0.184369^{*}$ & -0.096185 & 0.144053 \\
\hline & $(-2.882411)$ & $(-1.169297)$ & $(-1.625389)$ \\
\hline $\begin{array}{c}\text { Provincial } \\
\text { intercept }\end{array}$ & $\begin{array}{l}\text { Beijing: } \\
0.348076 \\
\text { Tianjin: } \\
\text { 0. } 194228 \\
\text { Hebei: } \\
\text {-0. } 49732 \\
\text { Liaoning: } \\
\text {-0. 136446 } \\
\text { Shanghai: } \\
\text { 0. 278537 } \\
\text { Jiangsu: } \\
\text { 0. 199316 } \\
\text { Zhejiang: } \\
\text { 0. 118245 } \\
\text { Fujian: } \\
\text {-0. } 021271 \\
\text { Shandong: } \\
\text {-0. } 008478 \\
\text { Guangdong: } \\
\text { 0. } 19865 \\
\text { Hainan: } \\
\text {-0. } 673535\end{array}$ & $\begin{array}{l}\text { Shanxi: } \\
-0.046994 \\
\text { Jilin: } \\
-0.01115 \\
\text { Heilongjiang: } \\
-0.05072 \\
\text { Anhui: } \\
-0.09349 \\
\text { Jiangxi: } \\
-0.193696 \\
\text { Henan: } \\
0.120445 \\
\text { Hubei: } \\
0.21547 \\
\text { Hunan: } \\
0.060135\end{array}$ & $\begin{array}{c}\text { Inner } \\
\text { Mongolia: } \\
\text { 0. 617894 } \\
\text { Guangxi: } \\
\text { 0. 386574 } \\
\text { Chongqing: } \\
\text { 0. 567275 } \\
\text { Sichuan: } \\
\text { 0. 292592 } \\
\text { Guizhou: } \\
\text {-0. 093034 } \\
\text { Yunnan: } \\
\text {-0. } 029594 \\
\text { Tibet: } \\
-1.681102 \\
\text { Shanxi: } \\
\text { 0. } 471366 \\
\text { Gansu: } \\
\text {-0. 162165 } \\
\text { Qinghai: } \\
-0.387329 \\
\text { Ningxia: } \\
\text { 0. } 071156 \\
\text { Xinjiang: } \\
-0.053633 \\
\end{array}$ \\
\hline Ad- $R^{2}$ & 0.971741 & 0.854328 & 0.945075 \\
\hline
\end{tabular}

Note: $\mathrm{T}$ statistic in parentheses $* * * \mathrm{p}<.01, * * \mathrm{p}<.05$, $* \mathrm{p}<.10$

\section{Conclusions and suggestions}

As for the deposit loan ratio, the increase of deposit loan ratio will lead to the economic growth of the eastern and central regions, but will reduce the economic growth of the western region. Therefore, the eastern and western regions need to reduce the deposit loan ratio to a certain extent, and the central region needs to increase the deposit loan ratio to a certain extent. The ways to increase the ratio of deposit to loan are as follows: first, reduce the interest rate of deposit to loan; second, provide preferential interest rate loans; third, the government should pay close attention to the construction of key projects and form a carrier and platform to attract loans; fourth, reduce the loan conditions and support the development of private enterprises; fifth, encourage banks to set up branches to guide the development of local banks ${ }^{[7]}$; sixth, severely punish the applicants for non-performing loans, and so on.

As for the industrial structure, the development of the tertiary industry will reduce the economic growth of the eastern and western regions, but will promote the development of the central region. The reason for this result is that the tertiary industry in the eastern region is developed enough, and further development will produce crowding out effect. Therefore, the eastern and central regions should develop the tertiary industry, while the western regions should not expand their development in 
this regard. The ways to develop the tertiary industry are as follows: first, using tax and other economic means to support the tertiary industry enterprises in line with the national development strategy; second, we should make use of foreign experience and technology to carry out various forms of reform; third, fully mobilize the enthusiasm of all sectors of society and encourage entrepreneurs to develop into the tertiary industry; fourth, promote the reform of personnel system, so that the tertiary industry enterprises can carry out independent employment; fifth, break the barriers of regions and industries, and promote the scale expansion of the tertiary industry.

As for fiscal expenditure, the increase of fiscal expenditure can promote the economic growth of the three regions, and from the perspective of coefficient, it can promote the economic growth of the western region the most. Some areas are very dependent on the government's fiscal expenditure, but the government should not blindly increase the amount of fiscal expenditure, but should pay more attention to the efficiency of fiscal expenditure. The ways to improve the efficiency of fiscal expenditure are as follows: first, carry out tax reform, reduce taxes and fees, consider new taxes, and reasonably divide the central and local tax revenue; second, special bonds should be issued to increase fiscal revenue, so that more expenditure can be made; third, maintain a general balance of revenue and expenditure.

As for foreign investment, the increase of foreign investment will reduce the economic growth of the eastern region and promote the economic growth of the central and western regions, and the increase of foreign investment will affect the economic growth of the central region more significantly. The reason for this result is that most foreign investors invest in the eastern region, but if too much foreign investment enters, it may erode the interests of domestic enterprises, so the coefficient is negative. The central region should strive to attract foreign investment through the following ways: first, to formulate incentive policies to attract foreign investment, such as preferential tax rates; second, to guide foreign investment to high-tech industries and promote the development of science and technology in $\mathrm{China}^{[8]}$; third, we should improve the quality of foreign investment and the level of utilizing foreign capital, and pay attention to the efficiency and output capacity of foreign investment.

As for insurance premium, the increase of per capita insurance premium will lead to the economic growth in the eastern and western regions. According to the development of China's insurance, we can improve it through the following methods: first, we should continue to improve the endowment insurance, life insurance and automobile insurance that the public often buy, so as to enhance the customer's service experience; second, improve the professional quality of insurance practitioners, eliminate the stereotype of the public on the insurance industry, and increase people's insurance demand; third, efforts should be made to improve the insurance awareness of farmers and other groups, speed up the development of insurance related to agricultural farmers, and improve rural financial services; fourth, improve and promote the relevant rules of insurance compensation, protect the legitimate interests of buyers, and create a positive brand image; fifthly, we should promote the innovation and reform of the insurance industry, create new insurance products, and build an insurance innovation pilot zone while continuing to promote the development of well-developed insurance, such as auto insurance.

\section{References}

1. Wanjun Xia, Gongju Yu. Research on the imbalance of regional economic development in China. Journal of Anhui Normal University (HUMANITIES AND SOCIAL SCIENCES) (2018)

2. Barthel. Research on the improper allocation of financial resources among regions in China and Its Correction--Taking Inner Mongolia as an example. Central University of Finance and economics (2017)

3. Dongyuan Li. Research on the balanced development of regional economy promoted by financial resources -- Taking Shandong Province as an example. Shandong University of Finance and economics (2014)

4. Yuhao Rong. Research on the influence of financial resources allocation on regional economic growth and Countermeasures -- Taking Beijing Tianjin Hebei as an example. Hebei University of Technology (2017)

5. Yunliang Liu. Spatial and temporal evolution of financial efficiency, regional differences and influencing factors: a case study of Hainan Province. Regional financial research (2019)

6. Ying Wei. An Empirical Study on the relationship between the imbalance of regional economic growth and the distribution of financial resources. Lanzhou Business University (2009)

7. Junqing Niu. Empirical analysis on the impact of regional financial development efficiency on economic growth. University of international business and Economics (2012)

8. Yajie Zhang, Xinwen Lin. An Empirical Study on the allocation efficiency of financial resources in Heilongjiang Province -- Based on the application of super efficiency DEA model. Commercial economy (2019) 